\title{
Outcome of pregnancy in relation to irregular and inconvenient work schedules
}

\author{
GÖSTA AXELSSON, RAGNAR RYLANDER, INGA MOLIN \\ From the Department of Environmental Hygiene, University of Gothenburg, S-400 33 Gothenburg, Sweden
}

\begin{abstract}
The relation between irregular and inconvenient working hours and the outcome of pregnancy was studied among women employed at a hospital in Sweden some time between 1980 and 1984. A questionnaire was distributed to 807 women; $81 \%$ replied. The pregnancies were divided into six groups with respect to work schedules during pregnancy. A slightly, but not significantly, increased risk of miscarriage was found in women who worked irregular hours or rotating shifts compared with women who worked only during the day $(R R=1 \cdot 44,95 \%$ confidence interval $0.83-$ 2.51). Infants of non-smoking mothers who worked irregular hours had significantly lower birth weights than infants of non-smoking women working day time only. This difference was largest at birth order $2+$. Similar results were found for infants of this birth order whose non-smoking mothers worked evenings or rotating shift.
\end{abstract}

Increased attention has been paid in recent years to the relation between occupational exposures and effects on reproduction and several reviews have been published..$^{-4}$

The studies have generally focused on effects from chemical exposures during pregnancy. In some, however, the influence of inconvenient or irregular work schedules and of stress have been discussed as possible causes of increased miscarriage rates among women working in operating theatres. ${ }^{56}$

In one study on pregnancy outcome among laboratory employees shift work during pregnancy was related to a significantly increased risk of miscarriage $(R R=3 \cdot 2){ }^{7}$ A relation between shift work and miscarriage rate was also found in a study on pregnancy outcome among women living near petrochemical industries in Sweden. ${ }^{8}$ The type of shift work was not described in these studies.

In Sweden $32.5 \%$ of all working women had irregular or inconvenient hours in $1982 .{ }^{9}$ Inconvenient working hours were defined as any work outside the period 0645-1745, and irregular working hours as work outside this interval not beginning or ending at the same time each day. Of all female employees, $3 \cdot 5 \%$ had a "pronounced shifting of work schedule" which described the situation primarily for women working at night within the public sector. Another 15.5\%

Accepted 13 June 1988 worked at different times of the day and night according to permanent schedules.

In the light of previous observations of an increased risk of miscarriage among women who report working shifts and the large number of women in Sweden working inconvenient or irregular hours, it was considered important to study further the risk of miscarriage among this group. It was also decided to investigate the relation between the particular periods during the day or night that women worked during pregnancy and the birth weight of the infant. Women working within the public health service were selected for the study.

\section{Subjects and methods}

All women born in 1934 or later who had worked at Mölndal Hospital in southwest Sweden some time between 1980 and 1984 could be identified using computerised employment registers. Six occupational groups were included in the study: nurses, nurses' assistants, nurses' aides, midwives, laboratory technicians, and $x$ ray assistants. All women permanently working nights were selected. A group of similar size within each occupational group but not working nights was randomly selected. In all, 821 women were included in the sample. A total of 807 could be located.

In April 1985 the 807 women were mailed a questionnaire on pregnancy outcome and working conditions during pregnancy. A reminder was mailed three weeks later to those who had not responded and 
a second reminder was sent after an additional three weeks.

Information was requested in the questionnaire on all pregnancies, including induced abortions and ectopic pregnancies. Other questions covered extent of employment, occupation, workplace and work schedules during the month before pregnancy, the first trimester, and the remainder of the pregnancy. Questions were also posed on possible exposures to chemicals, work with $x$ ray machines, and heavy lifting during pregnancy. Smoking habits, coffee consumption, illnesses, and intake of medication during pregnancy were also investigated.

Six different alternatives concerning work schedules were presented: always day, always evening, always night, irregular time (work at different times of day and night according to a permanent schedule), rotating shift (three shifts per 24 hours), and other working hours.

Questions related to pregnancy outcome were posed on the duration of gestation, delivery date, sex and birth weight of the child, and perinatal mortality. With regard to miscarriages, questions were asked as to when they had occurred and whether the miscarriage had been verified by a doctor.

Miscarriages reported in the questionnaire were included in the study only if they could be verified in hospital records or, if medical attention had not been obtained, if they were anamnestically reported in the records through later contacts with the medical system. The reviewing of records was permitted by an ethics committee.

The personal identification numbers of the subjects were linked to the Medical Birth Registry at the National Board of Health and Welfare. The Medical Birth Registry contains medical records in computerised form of all women who gave birth in Sweden after 1 January 1973. Information on birth weight, duration of gestation, Apgar score, and number of previous pregnancies was collected from this registry for deliveries that occurred after 1972 . For cases where the number of pregnancies in the questionnaire did not correspond to the data in the Medical Birth Registry, hospital records were investigated.

Information on the number of pregnancies among non-respondents was obtained from the departments of obstetrics and gynecology at the four largest hospitals in the region. For each pregnancy informa $\frac{2}{3}$ tion was collected on maternal age, year, outcome $\mathbb{\Phi}$ occupation, smoking habits, illness, and intake of. medication. Information was also sought on work $\overline{\bar{N}}$ schedules but was found only in occasional cases. Theo review of non-respondents' records was authorised by등 an ethics committee.

The miscarriage rate was defined as the number of miscarriages divided by the number of miscarriages $+\stackrel{2}{\circ}$ the number of induced abortions + the number of births. Ectopic pregnancies were thus excluded.

Possible risk factors for miscarriage, such as work with $x$ ray machines, anaesthetic gases, solvents, ${ }_{\infty}^{\omega}$ hexaclorophene, antineoplastic drugs, heavy lifting, smoking, and coffee consumption were analysed. The age adjusted relative risks for these factors werei calculated using the Mantel-Haenszel procedure. ${ }^{10}$ :

When calculating the adjusted relative risks foriw miscarriage related to work schedule, the material wasco stratified with regard to pregnancy number $(1,2+)$ 의 and smoking habits $(0,1-10,>10 \mathrm{cig} / \mathrm{day})$. Stratifica-tion was not done for number of previous miscarriages as there was no tendency toward overrepresentation of women having more than one miscarriage in any work $\overrightarrow{.}$ schedule group. Pregnancies begun before 1965 orog after 30 June 1984 were excluded.

The analysis of birth weights was based on information given in questionnaires. This method was considered acceptable as there was exact agreemento between the information in the questionnaire and theo Medical Birth Registry in $78 \%$ of the cases and as the difference in the mean weights for all children between $\overrightarrow{\vec{A}}$ these sources was only $2.6 \mathrm{~g}$. Test of significance was 3 made by using the Mann-Whitney $U$ test.

\section{Results}

In all, 654 of the $807(81 \%)$ women responded to the questionnaire of whom 463 had been pregnant at some 3 . time during the study period. Midwives had the highest response rate $(91 \%)$ whereas nurses' aides working nights had the lowest (74\%).

Table 1 shows the number of pregnancies among? respondents and non-respondents. A total of 970 을 pregnancies was reported in questionnaires; $9.7 \%$ of these resulted in miscarriage. Of the 998 pregnancies $\sigma$ among the respondents, 24 pregnancies $(2 \cdot 4 \%)$, N

Table 1 Outcome of pregnancies among respondents and non-respondents

\begin{tabular}{|c|c|c|c|c|c|}
\hline & Delivery & Induced abortion & Miscarriage & Total & Miscarriage rate (\%) \\
\hline $\begin{array}{l}\text { Respondents: } \\
\text { Data in questionnaire (verified) } \\
\text { Data not reported in questionnaire } \\
\text { Non-respondents } \\
\text { Total }\end{array}$ & $\begin{array}{r}787 \\
2 \\
159 \\
948\end{array}$ & $\begin{array}{r}89 \\
18 \\
61 \\
168\end{array}$ & $\begin{array}{r}94 \\
4 \\
28 \\
126\end{array}$ & $\begin{array}{r}970 \\
24 \\
248 \\
1242\end{array}$ & $\begin{array}{r}9.7 \\
16.7 \\
11.3 \\
10 \cdot 1\end{array}$ \\
\hline
\end{tabular}


Table 2 Outcome of pregnancies among respondents related to main activity during the first trimester

\begin{tabular}{|c|c|c|c|c|c|}
\hline & Delivery & Induced abortion & Miscarriage & Total & Miscarriage rate (\%) \\
\hline $\begin{array}{l}\text { Full time work } \\
\text { Part time work } \\
\text { Work at home } \\
\text { Studies } \\
\text { Disease } \\
\text { Unknown }\end{array}$ & $\begin{array}{r}331 \\
317 \\
100 \\
30 \\
9 \\
0\end{array}$ & $\begin{array}{r}29 \\
24 \\
10 \\
18 \\
1 \\
7\end{array}$ & $\begin{array}{r}38 \\
34 \\
16 \\
5 \\
1 \\
0\end{array}$ & $\begin{array}{r}398 \\
375 \\
126 \\
53 \\
11 \\
7\end{array}$ & $\begin{array}{r}9 \cdot 5 \\
9 \cdot 1 \\
12 \cdot 7 \\
9 \cdot 4 \\
9 \cdot 1 \\
-\end{array}$ \\
\hline
\end{tabular}

primarily induced abortions, were not reported in the questionnaires. The miscarriage rate among those who did not answer the questionnaire was larger than among the respondents $(11.3 \% v 9.9 \%)$. The total perinatal death rate was $0.95 \%$.

The miscarriage rate increased with pregnancy order and number of previous miscarriages. No relation, however, was found between maternal age and miscarriage risk, probably because only $4.5 \%$ of the pregnancies occurred in those aged 35 or over.

Table 2 shows the outcome of pregnancies reported in the questionnaire in relation to main activity during the first trimester. Gainful employment was reported during $80 \%$ of pregnancies. The highest miscarriage rate $(12.7 \%)$ was found among those who reported housewife status during pregnancy.

Table 3 shows the adjusted relative risk of miscarriage related to work conditions, smoking, and coffee consumption in the month before pregnancy and the first trimester. Women who reported exposure to solvents or hexaclorophene before or during the first trimester had the highest relative risks, although these were not statistically significant. Point estimates for $x$ ray work, exposure to anaesthetic gases, use of antineoplastic drugs, and heavy lifting were close to 1.0 .

A significantly increased risk of miscarriage was found for those who reported that they drank more than three cups of coffee a day during the first trimester. This increase was highest among nonsmokers $(R R=1 \cdot 67,0 \cdot 98-2 \cdot 85)$. Coffee consumption was not a confounder in this study, as this factor was evenly distributed within the work schedule groups.

The analysis of the relation between occupation during the first trimester and miscarriage risk showed that the group of laboratory technicians was the only one which had raised risk of borderline significance $(p=0.05)$. This group was small, however, and constituted only $2 \cdot 4 \%$ of all pregnancies among the respondents.

Table 4 shows the outcome of pregnancies and relative risks of miscarriage among respondents in relation to work schedules during the first trimester. Seventeen of 215 pregnancies $(7.9 \%)$ in the group of women who worked days only ended in miscarriage. After adjustment for pregnancy order and smoking habits, this rate was $8.5 \%$.

The highest miscarriage rates were found among women who reported irregular working hours or shift work. The adjusted relative risks were, however, not significantly increased in these groups. Among those who worked at night only, no tendency was seen toward an increased risk for miscarriage. As both "irregular time" and "rotating shift" mean that working hours are not regular, the combined relative risk for these groups was calculated $(R R=1.44$, $0 \cdot 83-2 \cdot 51)$.

The review of the hospital records of the 248 nonrespondents showed that a job title was named in 174 cases. In 19 pregnancies the women were engaged in study and housewife status was reported in another 29 cases. Information on occupation was missing in $\mathbf{5 0}$

Table 3 Adjusted relative risks of miscarriage related to work conditions, smoking, and coffee consumption in the month before pregnancy as well as during the first trimester

\begin{tabular}{|c|c|c|c|c|}
\hline & \multicolumn{2}{|c|}{ Month before pregnancy } & \multicolumn{2}{|l|}{ First trimester } \\
\hline & Relative risk & $95 \%$ Confidence interval & Relative risk & $95 \%$ Confidence interval \\
\hline $\begin{array}{l}\text { Work with } x \text { ray machines } \\
\text { Anaesthetic gases } \\
\text { Solvents } \\
\text { Hexaclorophene } \\
\text { Antineoplastic drugs } \\
\text { Heavy lifting }\end{array}$ & $\begin{array}{l}0.94 \\
0.90 \\
1.67 \\
1.40 \\
0.98 \\
1.04\end{array}$ & $\begin{array}{l}0 \cdot 52-1 \cdot 70 \\
0 \cdot 50-1 \cdot 61 \\
0 \cdot 88-3 \cdot 15 \\
0 \cdot 78-2 \cdot 52 \\
0 \cdot 32-2 \cdot 30 \\
0 \cdot 71-1 \cdot 51\end{array}$ & $\begin{array}{l}0.86 \\
0.93 \\
1.54 \\
1.44 \\
0.86 \\
0.99\end{array}$ & $\begin{array}{l}0.43-1 \cdot 71 \\
0.54-1.61 \\
0 \cdot 89-2.66 \\
0 \cdot 77-2 \cdot 70 \\
0.37-2 \cdot 01 \\
0.75-1 \cdot 31\end{array}$ \\
\hline $\begin{array}{l}\text { Smoking: } \\
1-10 \mathrm{cig} / \text { day } \\
>10 \mathrm{cig} / \text { day } \\
\text { Coffee: }\end{array}$ & $\begin{array}{l}0.73 \\
1.09\end{array}$ & $\begin{array}{l}0.42-1.26 \\
0.68-1.74\end{array}$ & $\begin{array}{l}1 \cdot 11 \\
1.41\end{array}$ & $\begin{array}{l}0.69-1 \cdot 78 \\
0.86-2.30\end{array}$ \\
\hline$>3$ cups/day & $1 \cdot 33$ & $0.98-1.80$ & 1.56 & $1.06-2.30$ \\
\hline
\end{tabular}


Table 4 Outcome of pregnancy and relative risks of miscarriage among respondents in relation to work schedule during the first trimester

\begin{tabular}{|c|c|c|c|c|c|c|c|}
\hline & Delivery & $\begin{array}{l}\text { Induced } \\
\text { abortion }\end{array}$ & Miscarriage & Total & $\begin{array}{l}\text { Miscarriage } \\
\text { rate }(\%)\end{array}$ & $\begin{array}{l}\text { Adjusted } \\
\text { relative risk }\end{array}$ & $\begin{array}{l}95 \% \text { Confidence } \\
\text { interval }\end{array}$ \\
\hline Always day & 185 & 13 & 17 & 215 & $7 \cdot 9$ & $1 \cdot 0$ & \\
\hline Always evening & 10 & 0 & 1 & 11 & $9 \cdot 1$ & 0.78 & $0 \cdot 11-5 \cdot 42$ \\
\hline Always night & 163 & 20 & 19 & 202 & $9 \cdot 4$ & 0.93 & $0.49-1.78$ \\
\hline Irregular hours & 240 & 15 & 30 & 285 & $10 \cdot 5$ & $1 \cdot 42$ & $0 \cdot 80-2 \cdot 50$ \\
\hline \multicolumn{8}{|l|}{ Rotating shift } \\
\hline (three shifts per $24 \mathrm{~h}$ ) & 37 & 2 & 5 & 44 & $13 \cdot 5$ & $1 \cdot 50$ & $0.55-4.09$ \\
\hline Other working schedule & 12 & 0 & 0 & 12 & - & - & \\
\hline Unknown & 1 & 3 & - & 4 & - & - & \\
\hline
\end{tabular}

cases. The miscarriage rate among those who worked during the first trimester was $13 \cdot 2 \%$.

Based on the work schedules reported in different occupational groups among the respondents and job titles in the non-respondent group, it was estimated that one third of the pregnancies in this group occurred in those who worked during the day, another third among those who worked "irregular time," and $25-30 \%$ among those who worked at night. It is unlikely that the miscarriage rate among the nonrespondents would change the relative risks shown in table 4 enough to make them significant values.

Table 5 shows birth weights of infants related to the main activity of the mothers during the second and third trimester. Infants of women in the non-respondent group were included in this table when information on occupation and smoking habits was found in hospital records. No significant differences between birth weights of infants of working mothers and other groups of infants could be found. The difference in birth weight between infants of smokers compared with non-smokers was $81 \mathrm{~g}$ at birth order 1 (NS) and $165 \mathrm{~g}$ at birth order $2+(\mathrm{p}<0.01)$. The increase in birth weight between birth order 1 and $2+$ was larger among non-smokers, $133 \mathrm{~g}(\mathrm{p}<0.01)$, than smokers, $48 \mathrm{~g}$ (NS).

Table 5 Birth weights of infants related to the main activity of the mothers during the second and third trimester

\begin{tabular}{|c|c|c|c|c|c|c|}
\hline & \multicolumn{3}{|c|}{ Birth order 1} & \multicolumn{3}{|c|}{ Birth order $2+$} \\
\hline & No & Mean & $S D$ & No & Mean & $S D$ \\
\hline $\begin{array}{l}\text { Gainful employm } \\
\text { Smokers } \\
\text { Non-smokers }\end{array}$ & $\begin{array}{l}\text { nt: } \\
146 \\
220\end{array}$ & $\begin{array}{l}3423 \\
3511\end{array}$ & $\begin{array}{l}478 \\
530\end{array}$ & $\begin{array}{l}108 \\
210\end{array}$ & $\begin{array}{l}3474 \\
3620\end{array}$ & $\begin{array}{l}623 \\
529\end{array}$ \\
\hline $\begin{array}{l}\text { Work at home: } \\
\text { Smokers } \\
\text { Non-smokers }\end{array}$ & $\begin{array}{l}7 \\
7\end{array}$ & $\begin{array}{l}3298 \\
3587\end{array}$ & $\begin{array}{l}307 \\
495\end{array}$ & $\begin{array}{l}29 \\
73\end{array}$ & $\begin{array}{l}3438 \\
3737\end{array}$ & $\begin{array}{l}666 \\
548\end{array}$ \\
\hline $\begin{array}{l}\text { Studies: } \\
\text { Smokers } \\
\text { Non-smokers }\end{array}$ & $\begin{array}{r}5 \\
16\end{array}$ & $\begin{array}{l}3492 \\
3288\end{array}$ & $\begin{array}{l}710 \\
792\end{array}$ & $\begin{array}{l}0 \\
2\end{array}$ & $\overline{3390}$ & $\overline{396}$ \\
\hline $\begin{array}{l}\text { Disease: } \\
\text { Smokers } \\
\text { Non-smokers }\end{array}$ & $\begin{array}{l}10 \\
12\end{array}$ & $\begin{array}{l}3542 \\
3710\end{array}$ & $\begin{array}{l}746 \\
605\end{array}$ & $\begin{array}{l}11 \\
23\end{array}$ & $\begin{array}{l}3680 \\
3553\end{array}$ & $\begin{array}{l}686 \\
592\end{array}$ \\
\hline $\begin{array}{l}\text { Total: } \\
\text { Smokers } \\
\text { Non-smokers }\end{array}$ & $\begin{array}{l}168 \\
255\end{array}$ & $\begin{array}{l}3427 \\
3508\end{array}$ & $\begin{array}{l}496 \\
555\end{array}$ & $\begin{array}{l}148 \\
308\end{array}$ & $\begin{array}{l}3476 \\
3641\end{array}$ & $\begin{array}{l}638 \\
540\end{array}$ \\
\hline
\end{tabular}

Table 6 Birth weights of infants related to work schedule of $\vec{\omega}$ the mothers during the second and third trimester

\begin{tabular}{|c|c|c|c|c|c|c|}
\hline & \multicolumn{3}{|c|}{ Birth order 1} & \multicolumn{3}{|c|}{ Birth order 2+ } \\
\hline & No & Mean & $S D$ & No & Mean & $S D$ \\
\hline \multicolumn{7}{|l|}{ Always day: } \\
\hline $\begin{array}{l}\text { Smokers } \\
\text { Non-smokers }\end{array}$ & $\begin{array}{l}55 \\
53\end{array}$ & $\begin{array}{l}3435 \\
3559\end{array}$ & $\begin{array}{l}449 \\
532\end{array}$ & $\begin{array}{l}23 \\
41\end{array}$ & $\begin{array}{l}3621 \\
3793\end{array}$ & $\begin{array}{l}395 \\
514\end{array}$ \\
\hline \multicolumn{7}{|l|}{ Always evening: } \\
\hline Smokers & 0 & $\overline{2}$ & - & 3 & 3260 & 147 \\
\hline Non-smokers & 1 & 2800 & - & 6 & $3073^{* *}$ & 226 \\
\hline \multicolumn{7}{|l|}{ Always night: } \\
\hline $\begin{array}{l}\text { Smokers } \\
\text { Non-smokers }\end{array}$ & $\begin{array}{l}14 \\
24\end{array}$ & $\begin{array}{l}3264 \\
3395\end{array}$ & $\begin{array}{l}543 \\
417\end{array}$ & $\begin{array}{l}44 \\
70\end{array}$ & $\begin{array}{l}3645 \\
3680\end{array}$ & $\begin{array}{l}526 \\
495\end{array}$ \\
\hline \multicolumn{7}{|l|}{ Irregular hours: } \\
\hline Smokers & 52 & 3476 & 501 & 24 & 3386 & 566 \\
\hline Non-smokers & 101 & 3461 & 509 & 59 & $3489 * *$ & 558 \\
\hline \multicolumn{7}{|l|}{ Rotating shift: } \\
\hline Smokers & 3 & 2997 & 307 & 2 & 3200 & $\begin{array}{l}636 \\
587\end{array}$ \\
\hline Non-smokers & 14 & 3754 & 843 & 11 & $3481^{*}$ & 581 \\
\hline
\end{tabular}

Table 6 shows birth weights of infants related to $\overline{\bar{\rho}}$ work schedules of the mothers during the second and third trimester. Infants of non-smoking women who had irregular work schedules had a significantly lowerbirth weight than infants of non-smoking womeno working during the day only. This difference was largest at birth order $2+(304 \mathrm{~g}, \mathrm{p}<0.01)$. At this birth order, infants of women who worked evenings or rotating shifts also had significantly lower birth? weights than infants of women who worked during the day only. No differences in gestational duration coulds be found between these groups. The same tendencys was seen in the corresponding groups among smokers? but these differences were not statistically significant. No

In 17 of those 784 cases $(2.5 \%)$ where the mothers worked during pregnancy the birth weight was lesso than $2500 \mathrm{~g}$. An overrepresentation of low birthweightw infants could not be found in any work schedule group.

\section{Discussion}

This investigation was based on pregnancies occurringo during the period 1965-84 among women who workedब at a hospital some time between 1980 and 1984. 
Pregnancies in the same period among women who had terminated their employment before 1980 are thus not included. It has previously been shown that women who were working at the time of the study might have a higher miscarriage rate than those who had stopped working because many women stopped working after childbirth ${ }^{11}$ in the 1960 s and beginning of the 1970s. As most pregnancies occurring in the decades concentrated on in this study were found among women who had resumed work some years after the birth of the last child, it is unlikely that the pregnancy outcome before 1980 is biased.

Response bias in studies of miscarriage has previously been shown. ${ }^{12}$ The number of pregnancies in the non-respondent group was therefore obtained from hospital records. Even if the information on work schedules among the non-respondents in general was based on an estimation, it is unlikely that pregnancy outcome in the non-respondent group essentially affects the calculated relative risks for miscarriage.

Regarding risks of miscarriage in relation to work schedule, comparisons were made with the group characterised as "always day." The results did not support the hypothesis that night work is associated with an increased risk of miscarriage. As the proportion of part time workers among women working nights was high $(91 \%)$, possible effects of full time work at night cannot be evaluated from this study.

The largest group in this study constituted pregnancies among women who reported "irregular time." The proportion of full time work in this group was $69 \%$. It was not possible to make any further division of pregnancies during irregular work schedules. Different clinics have their own particular schedules, and up to seven different schedules may be seen within one clinic. In general, different occupational groups within one clinic have the same schedule. In all clinics evening work at least once a week was included in the schedule.

No significantly increased risk of miscarriage could be shown among women having "irregular work schedules." If the risk of miscarriage in this group had been twice as high as in those who worked days only the probability of detecting that increase would have been $80 \%$.

The highest relative risk (although not significant) was seen among those who worked rotating shifts $(R R=1 \cdot 50)$. Only midwives reported such work. The previously observed high risk of miscarriage associated with shift work $(R R=3 \cdot 2)^{7}$ could thus not be found in the present study. The reason for this could be that the previous observation was a random event or that shift work in that study was not clearly defined. As the number of pregnancies in the present study was small, a threefold risk could not be excluded.
McDonald et al reported in a study from Montreal that the number of miscarriages among women working rotating shifts in "health occupations" was 131 , compared with 114 expected. ${ }^{13} \mathrm{~A}$ further analysis of all occupations in this large study showed that shift work was associated with signifiantly increased relative risk $(R R=1.45,1.0-1.9) .{ }^{14}$ These results, in addition to the results from the present study, indicate that the increased risk of miscarriage implied by shift work is not as large as might be expected from the initial reports.

Birthweight distribution has been suggested as an indicator of environmental effects on fetal development. ${ }^{15} \mathrm{~A}$ review of employment and birth weight concluded that a relation between gainful employment and low birth weight has not been seen in most studies conducted after $1970 .^{16}$

Only a few studies on work schedules and birth weight have been published. Saurel-Cubizolles and Kaminski reported that no increased frequency of infants with low birth weight could be found when the mother worked at night. ${ }^{17}$ McDonald et al reported that changing shift work was significantly related to low birth weight. ${ }^{18}$

In the present study the birth weights of infants with birth order $2+$ and with non-smoking mothers were significantly lower when the mother reported work at evening, irregular work schedules, or shift work than in those infants whose mothers worked days only. The same tendency, although not significant, was seen in smokers. The increase in mean birth weight between birth order 1 and $2+$ in infants of women who had irregular work schedules was small among non-smokers and not seen at all among smokers. These results support the hypothesis that irregular work schedules have a negative influence on birth weight. Chattingius et al reported from a prospective study on factors influencing birth weight that the expected increase in birth weight with increasing birth order did not occur when a risk factor such as smoking or previous birth of a low birth weight infant was present. ${ }^{19}$

In the present study only $2.5 \%$ of the children whose mothers worked during pregnancy had a birth weight less than $2500 \mathrm{~g}$. Ericson et al reported that this proportion in all infants in Sweden born in 1976-7 was $4.4 \%{ }^{20}$ There was no tendency toward overrepresentation of low birth weight in any work schedule group.

Even if the weight and height of the mother influence the birth weight, and thus are possible confounders, these factors are unlikely to be associated with work schedules. Neither is age a probable confounder. Ericson et al showed that there is an increased risk of low birth weight if the mother is under 20 or over 35 at the birth of the first child. ${ }^{15}$ Only $6 \%$ of the deliveries among the working women fall into these categories. 
Stress during pregnancy has been reported as a possible risk factor for low birth weight. Mamelle and Munoz found that work considered stressful increased the risk of premature birth. ${ }^{21}$ Psychosocial stress in pregnancy has also been associated with reduced birth weight. ${ }^{22}$

Irregular work schedules are possibly more stressful than day work only. No questions concerning stress were induced in the questionnaire. It is thus not possible to determine whether irregular diurnal rhythm, stress, or some unidentified confounder is the cause of the reduced birth weights observed in infants of mothers who worked irregular hours, rotating shifts, or evening schedules.

Shift work or other strongly irregular work schedules could lead to a change in the circadian rhythm. The relation between circadian rhythm and influence on reproduction is poorly understood. Seibel et al found that the level of preovulatory luteinising hormone in most women increases in the early morning, suggesting a circadian regulation of the ovulatory cycle in women. A high frequency of menstrual irregularities has been reported among airline stewardesses, an occupational group commonly exposed to shifts of the circadian rhythm. ${ }^{24}$ Whether such shifts may also influence pregnancy outcome is not known.

If the results from the present study should be found in other studies the work schedule of the mother will be seen to be a potential confounding factor in many studies on environmental factors and birth weight. Further epidemiological studies on the relation between work schedule and pregnancy outcome are thus strongly motivated.

This work was supported by a grant from the Swedish Work Environment Fund (83-0179).

\section{References}

1 Hemminki $K$, Vainio $H$. Occupational epidemiology and reproduction. In: Harrington $\mathrm{JM}$, ed. Recent advances in occupational health. London: Churchill Livingstone, 1984: $117-30$.

2 Lindbohm M-L, Taskinen H, Hemminki K. Reproductive health and working women: spontaneous abortions and congenital malformations. Public Health Rev 1985;13:55-87.

3 Kleine J. Maternal occupation: effects on spontaneous abortions and malformations. Occupational Medicine: State of the Art Reviews 1986;1:381-403. Axelsson, Rylander, Molin

4 Rosenberg M, Feldblum P, Marshall E. Occupational influencês on reproduction: a review of recent literature. J Occup M 1987;29:584-91

5 Vaisman AI. Work in surgical theatres and its influence on the health of anaesthesiologists. Eksperimentalnaja Khirurgi Anesteziologija 1967;12:44-9.

6 Rosenberg P, Kirves A. Miscarriages among operating theatre staff. Acta Anaesthesiol Scand 1973;53(suppl):37-42.

7 Axelsson G, Lütz C, Rylander R. Exposure to solvents ar outcome of pregnancy in university laboratory employees. $B r \bar{\Omega}$ Ind Med 1984;41:305-12.

8 Axelsson G, Molin I. Outcome of pregnancy among women livirf: near petrochemical industries in Sweden. Int $J$ Epidemial 1988;17:363-9.

9 Official Statistics of Sweden. Irregular and inconvenient hours of work. (Report No 37.) Stockholm: Official Statistics of Swedenu 1983. (In Swedish.)

10 Mantel N, Haenszel W. Statistical aspects of the analysis of da from retrospective studies of disease. JNCI 1959;22:719-48.

11 Axelsson G. Selection bias in studies of spontaneous abortiop among occupational groups. J Occup Med 1984;26:525-8. .

12 Axelsson G, Rylander R. Exposure to anaesthetic gases and spontaneous abortion: response bias in a postal questionnaie study. Int J Epidemiol 1982;11:250-6.

13 McDonald A, Armstrong B, Cherry N, et al. Spontaneos abortion and occupation. J Occup Med 1986;28:1232-8.

14 McDonald AD, McDonald JC, Armstrong B, et al. Fetal death and work in pregnancy. Br J Ind Med 1988;45:148-57.

15 Ericson A, Eriksson M, Källén B, Meirik O. Birthweight distrib tion as an indicator of environmental effects on fetal development. Scand J Soc Med 1987;15:11-7.

16 Saurel-Cubizolles MJ, Kaminski M. Work in pregnancy: iष evolving relationship with perinatal outcome (a review). Soc S Med 1986;22:431-42.

17 Saurel-Cubizolles MJ, Kaminksi M. Pregnant women's workin conditions and their changes during pregnancy: a national stuof in France. Br J Ind Med 1987;44:236-43.

18 McDonald AD, McDonald JC, Armstrong B, Cherry NM, Nol $\mathrm{AD}$, Robert $\mathrm{D}$. Prematurity and work in pregnancy. $\mathrm{Br} \mathrm{J}$ Ind Med 1988;45:56-62.

19 Cnattingius S, Axelsson O, Eklund G, Lindmark G, Meirik $\overrightarrow{\hat{Q}}$ Factors influencing birthweight for gestational age, with specia respect to risk factors for intrauterine growth retardation. Ear Human Development 1984;10:45-55.

20 Ericson A, Eriksson M, Westerholm P, Zetterström R. Pregnancy outcome and social indicators in Sweden. Acta Paediatr Scand 1984;73:69-74.

21 Mamelle N, Munoz F. Occupational working conditions and preterm birth: a reliable scoring system. Am J Epidemiol 1987 126:150-2.

22 Newton R, Hunt L. Psychosocial stress in pregnancy and if relation to low birth weight. Br Med J 1984;288:1191-4.

23 Seibel M, Shine W, Smith D, Taymor M. Biological rhythm of the luteinizing hormone in women. Fertil Steril 1982;37:709-11.

24 Preston FS, Bateman SC, Short RV, Wilkinson RT. The effects flying and of time changes on menstrual cycle length and of performance in airline stewardesses. In: Ferin M, Halberg $\mathbb{N}$ Richard RM, Van der Wiele RL, eds. Biorhythms and human reproduction. New York: John Wiley, 1974:501-12. 